\title{
The Role of Conspiracy Mentality and Paranormal Beliefs in Predicting Conspiracy Beliefs Among Neopagans
}

\author{
Asbjorn Dyrendal ${ }^{\mathrm{I}}$, Leif Edward Ottesen Kennair ${ }^{\mathrm{I}}$ and \\ JAMES R. LEWIS ${ }^{2}$
}

1. Norwegian University of Science and Technology 2. University of Tromsø

Recent studies on conspiracy thinking has concluded that the strongest predictor of the tendency towards conspiratorial thinking is a one-dimensional construct - conspiracy mentality - that is relatively stable over time and valid across cultures. Lantian et al. (2016) found that a single, elaborate question can work as a measure of conspiracy beliefs. We assess the validity of this question for an untypical, religious group: self-identified Neopagans. We also test some recent findings on the relation between conspiracy thinking and paranormal beliefs, attitudes towards group equality, political identification, age, gender, and education. The general patterns hold up well in our investigation, but there was a clear distinction between conspiracy theories about powerful actors and those about minorities. The single-item measure was the largest predictor of the former kind of conspiracy belief followed by level of paranormal beliefs. Anti-egalitarianism and holding a right-wing political identity were the strongest predictors of conspiracy beliefs about minorities. Education was negatively related to conspiracy beliefs of all kinds.

\section{Introduction}

The study of conspiratorial ideations has become a robust field of research over the last few years, covering multiple academic disciplines, geographical areas and historical epochs (Bilewicz, Cichocka and Soral 2015; Butter 2014; Butter and Reinkowski 2014; Gray 2010; Uscinski and Parent 2014). While research pertaining to conspiracy belief in religious groups goes back some decades (e.g. Aho 1990; Barkun 1994), most studies are more recent (e.g. Gardell 2003; Goodrick-Clarke 2003; Dyrendal, Robertson and Asprem in 
press). Both older and more recent research has relied almost completely on qualitative methods analyzing conspiracism in its lived context, or describing the historical background for and uses of conspiracy theories. This is also true for conspiracy beliefs in new religious movements and within less organized forms of alternative spirituality (Asprem and Dyrendal 2015; Aupers 2012; Dyrendal 2017; Robertson 2016; Roeland, Aupers and Houtman 2012).

There is thus a dearth of quantitative studies pertaining to conspiracy belief and religion from within the disciplines primarily studying religion, but studies in other fields have found relevant measures, regarding, for instance, commonalities in cognitive patterns underlying beliefs, and personality traits that select for certain styles of belief (see Wood and Douglas, in press).

One general-level result is that paranormal beliefs relate to, and predict, conspiracy belief (Bruder et al. 2013; Darwin, Neave and Holmes 2011; Lobato et al. 2014). The paranormal category is typically tied to folk beliefs and/or unconventional religious beliefs. There is some sense to separating such beliefs in this context, as other, more theologically-conventional (establishment) supernatural beliefs show small, uncertain, or no connections to conspiracism (e.g. Oliver and Wood 2014, 961f).

Perhaps the most influential among the founding texts in the study of conspiracy culture defined a conspiracy-prone "paranoid style" as Manichean and apocalyptic (Hofstadter 1964). This opinion has been echoed in empirical, qualitative studies (Barkun 2003), and a recent investigation of a representative sample of Americans that found end time belief and a Manichean worldview outperformed paranormal beliefs as predictors of belief in a series of conspiracy theories. It also outperformed a single-item measure of conspiracy mentality (Oliver and Wood 2014 961).

This could point to the general worldview of the relevant population, i.e. belief consonance, as being the most salient issue in explaining conspiracy beliefs, as partially argued by Barkun (2003). The relation between apocalypticism and conspiracism (Oliver and Wood 2014), and "alternative" beliefs and conspiracism (Lobato et al. 2014), could also be interpreted to show that conspiracy beliefs of certain kinds follow other, common beliefs in the relevant milieu; group members believe as their ingroup does. However, the correlation between paranormal belief and conspiracy thinking seems also to be partially driven by personality factors and individual differences (e.g. Barron et al. 2014; Barron et al. 2018; Brotherton and French 2015; Darwin et al. 2011; Swami et al. 2011). These should again combine with social circumstances and relate systematically to different types of religion (e.g. Farias and Granquist 2006; Asprem and Dyrendal in press), given that underly-

(C) Equinox Publishing Ltd. 2018 
ing traits related to conspiracy beliefs— such as authoritarianism (Altemeyer 1994; Stenner 2004), social dominance orientation (Sidanius and Pratto 1999), and conspiracy mentality (Imhoff and Bruder 2014) — seem to partially depend on socialization and activation in social interaction. Factors such as values, beliefs, social structure and situation should, therefore, all influence group belief in conspiracy together with personality factors and individual differences. However, we have no within-group studies that permit us to say that factors such as paranormal beliefs will still be evident in a sample where the majority holds the same worldview, very much including paranormal beliefs. Previous research has not addressed how these psychosocial mechanisms work within specific minority groups, such as the current Neopaganist sample, where specific paranormal beliefs are normally associated with but do not define the religious minority.

\section{Neopagans and the political dimension of conspiracy beliefs}

Neopaganism, often called "contemporary Paganism" or merely Paganism, is a category that points to a highly diverse group of beliefs and practices, organized in everything from close-knit groups to loose networks and solitary practitioners. Previous, quantitative research into North American Pagans suggests that they "tend to be well-educated, middle class, and disproportionately female" (Berger 2009, 157; cf. Lewis, Currie and Oman-Reagan 2016). They live mostly in urban or suburban areas, and while many deem themselves apolitical, they are more politically active than average Americans. The "Neopagan" category includes everything from anarcho-feminist varieties of Wicca to the most right-wing, racialist Odinism. It is thus not merely politically diverse, but partially separated into political "enclaves." The largest part of Neopaganism by far is, according to research, left-of-center, with even the mainstream right being a small minority (Berger 2009, 163).

This means that many hold strongly egalitarian values and may combine these with a skeptical attitude towards 'the establishment'. Pagans are, other than far right-versions, very unlikely to hold either a Manichean worldview or apocalyptic expectations, but many hold a number of paranormal beliefs. All these traits make the group interesting as a case study.

This goes, not least, for the political dimension. Beliefs in conspiracy theories have been viewed as sufficiently unidimensional to be treated as one of several generalized political attitudes—conspiracy mentality. As such, Imhoff and Bruder (2014) found that a five-item measure of conspiracy mentality predicts suspicion of and belief in conspiracy from what is considered socially powerful groups more reliably than competing measures of generalized polit-

(C) Equinox Publishing Ltd. 2018 
ical attitudes, whereas measures such as right-wing authoritarianism (RWA; Altemeyer, 1981) and social dominance orientation (SDO, Sidanius, and Pratto, 1999) correlate more with conspiracy theories about groups lower in the social order.

\section{Aims and predictions}

The primary aim of this study was to investigate how research findings on conspiracy beliefs stand up when the population being studied shares a specific religious identity with attendant worldview.

\section{Validity of a one-item scale for conspiracy beliefs}

Conspiracy belief has, as mentioned above, generally been shown to be a unidimensional construct; belief in one conspiracy predicts belief in others (e.g. Bruder et al. 2013; Dagnall et al. 2015; see Goertzel 1994). However, the scales attempting to measure this construct (e.g. Brotherton, French, and Pickering 2013; Bruder et al. 2013) have consisted of too many items to suit all occasions. In an effort to accommodate research where space or avoiding attrition in participants is at a premium, a French-British team (Lantian $e t$ al. 2016) recently validated a single-item scale on French students and an American sample of on-line participants. The question primes the audience by mentioning the $9 / 11$ attacks, the death of Princess Diana and JFK as events that are debated, before asking whether the "official version" of these events are a cover-up of "the fact that these events have been planned and secretly prepared by a covert alliance of powerful individuals or organizations" (Lantian et al. 2016, 10).

While the original authors do not make this assertion, we find that the measure in its directionality and what it encompasses should work similar to other measures of conspiracy mentality, and will address it as such in our test of this prediction. We expect the single-item conspiracy beliefs scale to predict a series of conspiracy beliefs in a very different population from the original trials, and to cover more than "a sub-dimension of conspiracy beliefs" (Lantian et al. 2016, 9).

\section{Paranormal Beliefs}

Paranormal beliefs have been shown to correlate positively with conspiracy beliefs (Darwin, Neave and Holmes 2011; Lobato et al. 2014; Swami et al. 2011). The relation seems to be partially mediated by e.g. schizotypy (Barron et al. 2014; Barron et al. 2018), and the strength of the relation between paranormal ideation and conspiratorial ideation varies between investigations,

(C) Equinox Publishing Ltd. 2018 
from small to large, with a low of $\mathrm{r}=0.15$ (Swami et al. 2011) and a high of $\mathrm{r}$ $=0.52$ (Lobato et al. 2014). Moreover, the investigations have been conducted on different populations (from student samples to representative selections), in different countries, and by a variety of measures of both paranormal beliefs and conspiracy theories. There is thus good reason to expect the relation to hold up, but no good reason to expect any specific size for the correlation.

While the paranormal beliefs here partially overlap with varieties of validated paranormal belief scales (e.g. Tobacyk and Milford 1983; Tobacyk, 2004), they are not directly comparable with regard to their dimensionality. Some known dimensions (cf. Stone et al. 2018) are covered. We have questions covering belief in anomalous mental powers, such as clairvoyance and telepathy, the survival dimension (reincarnation, mediumism), and extraordinary lifeforms (UFOs and extraterrestrial visitors). Topics such as "traditional supernatural beliefs" (Stone et al. 2018, 147) are, however, shaped by earlier investigations of Pagan beliefs with data from both earlier versions of the Pagan Census and broader census data (Berger, Leach, and Shaffer 2003; Lewis and Tøllefsen 2013). Thus, topics such as casting spells are formulated in relation to energy beliefs ("energy-based therapies") in the statement that "stones and crystals can have magical powers". Alternative therapies are covered by two general questions. Religious beliefs specific to and defining of Paganism are not included in this set of questions.

We predict that paranormal beliefs will be associated with conspiracy beliefs, and also correlate with gender and education. Furthermore, we wish to explore how paranormal beliefs relate to conspiracy stereotypes about religious minorities.

\section{Conspiracy theories: Powerful vs discriminated groups}

Conspiracy mentality has shown itself to predict belief in conspiracy theories directed upwards towards those deemed to be more powerful better than conspiracy beliefs directed downwards toward discriminated groups (Imhoff and Bruder 2014). This has, however, been done with other scales than the singleitem question constructed by Lantian et al. (2016). Nevertheless, we predicted that the measure would still more accurately predict theories towards groups deemed more powerful, and that SDO-E would better explain conspiracy beliefs about the two religious minorities.

\section{Extremes at Right and Left}

Some recent research shows that the extremes on a left-right political scale are more prone to embrace conspiracy beliefs (van Prooijen, Krouwel, and Pollet, 
2015; Krouwel et al. 2017). This is, however, a point of debate, with other research showing no important difference on a left-right scale (Uscinski and Parent 2014). Since some of these researchers stress instead that "conspiracy theories are for losers" (Uscinski and Parent 2014, 130-153), i.e. those out of power, and extremists have tended to be outside of power, this may explain why a fine-tuned political scale would show extremes to be more conspiracyprone.

There was always a small chance that the snowballing process of data collection for this survey could extend to the far right, in which case we would expect some variant of the distribution-curve found by van Prooijen, Krouwel, and Pollet (2015). We expected that the far right would generally score higher on both dominance and on the "conspiracy stereotype"-related questions about minorities. We expected further that they would score highest on both the general measure of conspiracy belief and the particular theories, mostly on the strength of written sources and fieldwork (e.g. Gardell 2003, but compare Imhoff 2015).

\section{Participation vs non-participation}

Some conspiracy theories are part of populist rhetorical mobilization, for instance through atrocity tales about the opposition and its evil plans. General outsider-status seems to affect conspiracy beliefs (e.g. Goertzel 1994), and recent research intimates that conspiracy belief may affect participation in conventional political arenas negatively (Jolley and Douglas 2014; Uscinski and Parent 2014). Given recent history before March 2016, we therefore expected that those who reported participating in elections would score lower on conspiracy beliefs than those who chose not to.

\section{Sex differences}

Swami et al. found a significant sex difference in conspiracy beliefs, and stated that "[c]learly, sex differences in conspiracy ideation are an idea that requires further research" $(2011,460)$. Their statement was plausible on the strength of an established relationship between paranormal beliefs and biological sex (Farias, Claridge and Lalljee 2005; Lindeman and Aarnio 2006; Tobacyk and Milford 1983). When we know that paranormal beliefs also predict conspiracy beliefs, we might expect to see a similar relationship. More broadly, however, research indicates that there is no sex difference in level of conspiracy belief (Bruder et al. 2013; Goertzel 1994; van der Tempel and Alcock 2015; Wagner-Egger and Bangerter 2007). At least over a broad spectrum of conspiracy theories, both sexes seem to have the same level of belief. A cross-cultural investigation found an effect only for the United States,

(C) Equinox Publishing Ltd. 2018 
where women scored slightly higher than men (Bruder et al. 2013). Recently however, Freeman and Bentall $(2017,597)$ found American men to be more conspiracy prone than women. We therefore expected no or only very small sex differences in conspiracy beliefs relating most to conspiracy mentality. We expected men to be less egalitarian, consistent with general findings on social dominance orientation (e.g. Pratto, Stallworth, and Sidanius 1997) and therefore score higher on our items of conspiracy theories about Jews and Muslims.

\section{Level of education}

Level of education seems to weakly predict lower conspiracy beliefs (e.g. van Prooijen 2017; but see Imhoff and Bruder 2014, 28). There are sound reasons to expect that this finding holds up, in that analytical thinking skills and habits (e.g. Swami et al. 2014), as well as increased knowledge (e.g. Swami et al. 2011) have, in different investigations, all been demonstrated to predict less adherence to conspiracy beliefs.

We wanted to first test whether level of education influences level of (dis) belief in conspiracy theories for this population. Since education may also predict a similar decrease in levels of paranormal beliefs (see Aarnio and Lindeman 2005; cf. Orenstein 2002), a secondary interest was in whether it then also was associated with belief in paranormal issues.

Table 1 provides a list of our predictions.

Table 1. Key and minor predictions

Key predictions

1. Validation of the one-item CMQ

a) The one-item CMQ will be valid.

b) The one-item CMQ will predict conspiracy beliefs about authorities better than about minorities

2. SDO will best predict conspiracy beliefs about minorities

3. Paranormal beliefs predict conspiracy beliefs.

4. Political extremism predicts conspiracy beliefs.

\section{Minor predictions}

5. Sex differences in conspiracy beliefs and paranormal beliefs

a) Men will score higher on conspiracy beliefs about minorities.

b) Women will score higher on paranormal beliefs.

c) There will be no differences between the sexes in general conspiracy beliefs.

6. Political non-participation will also be positively correlated with conspiracy beliefs

7. Education will correlate negatively with both conspiracy beliefs and paranormal beliefs. 


\section{Method}

\section{Procedure}

The loose network structure of Paganism means that the Pagan III survey was, like its forebears, collected online, as a convenience sample. It was posted on Survey Monkey, notification was sent out through a network of Paganism scholars, picked up by Pagan social networks and Pagan sites working as community news outlets, and respondents outside of these primary groups were recruited through a network-snowballing method. The one to which notice of, and invitation to take the survey, was actively posted, the Witches' Voice, is the largest such site and reaches broadly into Pagan communities, and presents as politically neutral. In practice, however, its reach into the far-right corner is limited. Other venues cater to more select parts of the Pagan community, and it is thus much more likely that our respondents hail from similar types of Pagan identity. The end result is that we have very few respondents representing the political minority on the far right.

The Pagan surveys are primarily a kind of repeated cross-sectional study, done on convenience samples recruited online. Their primary purpose is to map developments in reported primary beliefs and related activities over time. This gives descriptive data on a broader scale and with the possibility of seeing larger patterns than through participant observation alone.

All survey questions were visible to respondents when opening the document. They could get an overview of all questions and choose whether to respond to any one of them. Moreover, the way the survey itself was disseminated meant that they could have foreknowledge about both questions and internal discussions about them. This will have opened for a certain amount of social influence on what to expect, and on whether and how to answer.

\section{Respondents}

We downloaded material for this analysis on March 31st, 2016 after the initial waves of responses had tapered off. At the time, there were a total of 1756 respondents. For most of the relevant variables, we have 1740 or more valid answers. There was a clear female predominance $(\mathrm{n}=1144)$ over men $(\mathrm{n}=$ 537) and those identifying as "other, including those transitioning" ( $\mathrm{n}=63$ ) in the sample. Originating from more than 40 countries, almost two thirds were from the United States $(64.75 \%, \mathrm{n}=1135)$, followed by the United Kingdom $(12.3 \%, \mathrm{n}=210)$, and Canada $(6.7 \%, \mathrm{n}=118)$. Other countries, counted separately, mostly accounted for single to low double digits. 
The respondents were highly educated. More than half (54.9\%) had a bachelor's degree or above (master $=19 \%$; doctoral or law degree $=5.7 \%$ ). The vast majority $(89.5 \%)$ had at least one year of college or a technical diploma (7.8\%). Only $1.9 \%$ reported not having a high school diploma, most of whom are either too young to have finished high school or at an age where they are likely to graduate in short time. Level of education was grouped into four groups: no college, some college, finished bachelor's degree, and completed master's degree or higher. The mean age was 42 , with the oldest respondent born in 1937, the youngest in 2000 .

\section{Measures}

\section{Conspiracy mentality}

Conspiracy mentality was measured by the one-item conspiracy beliefs scale of Lantian et al. (2016).

\section{Conspiracy beliefs}

The survey contained twelve questions relating to conspiracy beliefs, i.e. "accusatory perceptions [about conspiracy] that may or may not be true" (Uscinski and Parent 2014, 33). Five were of a general order, measuring attitudes of suspicion that powerful actors secretly work in ways that may be counter the interests of the general citizenry ("There are hidden groups that significantly influence political decisions"). Five questions were more closely related to specific conspiracy lore about powerful actors ("Knowledge of - and/or progress toward - a cure for cancer, AIDS, and other profitable diseases is deliberately being hindered by Big Pharma”). Two reverse-phrased items concerned conspiratorial dispositions of Jews and Muslims and appeals to conspiratorial group stereotypes (see e.g. Winiewski, Soral, and Bilewicz 2015).

Principal component analysis showed two factors involved. The five general and the five more specific were all related along the same dimension. However, the factor analysis confirmed our expectations of a significant difference between the two conspiracy theories related to Muslims and Jews and the ten others. The correlation between the two groups of theories was significant ( $p$ $<0.001)$, but so low as to be effectively meaningless $(r=0.07)$. The analysis therefore looks at these two groups separately.

Conspiracy theories were thus factored into two subscales: ten highly related items $(\alpha=0.90)$ of general conspiracy beliefs about mainstream, powerful sources (CT-10), and two items of conspiracy stereotype-related beliefs about 
Muslims and Jews (CS-2). Even with only two items, this showed acceptable consistency $(\alpha=0.71)$. For the conspiracy theories, the mean was calculated on those who had answered at least seven of ten items (i.e., one might have up to three missing values and still have the mean calculated); for conspiracy stereotypes, both items had to be answered. We also ran analyses of the latter separately for relevant questions.

\section{Paranormal beliefs}

The paranormal beliefs-questions follow broad, observation-based topics of beliefs in the wider milieu in which Pagans are situated. The items were grouped together based on responses to earlier Pagan surveys, items from the Baylor University (2005) survey, and relevant topics from Bader et al. (2010). From this we constructed a preliminary scale of 23 items (PBS-23). Internal consistency was high, $\alpha=0.93$.

Factor analysis revealed four groups of components which seem to relate more to worldview differences within Paganism than to the factor structure found in general population surveys. The largest group of components involved twelve items most closely related to folk, New Age-ideation and practices (PBS-NA; $\alpha=0.93$ ); the second had four items more resembling those associated with New Age sensu stricto (Hanegraaff 1996; PBS-NASS; $\alpha$ $=0.68$ ); three items related to western appropriations of karma in one interpretation or other (PBS-IND; $\alpha=0.79)$. Of the final four items, three were most clearly related to alternative history and UFO-ideas (PBS-UFO; $\alpha=$ 0.82). A final, anti-modern item, was not formulated to measure specifically paranormally related anti-modernism, and it was so weakly related to other items that it was dropped from analyses other than the full scale.

For the full 23-item scale, we used the mean score of at least 20 items in calculations. For PBS-NA we ran the calculations with the mean of at least ten of twelve items; for the others, the mean score of all.

\section{$S D O-E$}

We used the eight con-trait items from the anti-egalitarianism scale (SDO-E) of SDO-6 (Sidanius and Pratto 1999; for later development, see Ho et al. 2012, 2015). ${ }^{1}$ The items showed excellent internal consistency $(\alpha=0.93)$. $\mathrm{SDO}-\mathrm{E}$ is skewed in this population $(-1.47)$, but within the range of normality. In calculations, we used the mean score on at least six items.

1. The items making up the dominance dimension of SDO-6 (the SDO-D) are formulated in such a brutal manner, and run counter to the predominant Pagan ethos to such a degree that it was judged likely to interfere with recruiting respondents.

(C) Equinox Publishing Ltd. 2018 
Scores

All questions about conspiracy theory, social dominance, and paranormal beliefs were scored on a five-point Likert scale, with the third item explicitly denoted as "undecided/neutral." Political affiliation was measured on a 1-10 scale with 11 as "unpolitical." The conspiracy mentality question was per Lantian et al. (2016) measured on a nine-point scale.

Statistical Analysis

The data from Survey Monkey was imported into IBM SPSS 24, which was used for all data summaries and analyses.

\section{Results}

The mean score on the ten conspiracy theory items (CT-10) was 2.52 ( $\mathrm{n}=1750$ ), somewhat on the believing side of undecided. The mean score on the reverse-phrased items about Jews and Muslims (CS-2) was 1.90 $(\mathrm{n}=1749)$, clearly skeptical towards these conspiracy theories. The mean score one the one-item question about conspiracy mentality was 5.76 $(\mathrm{n}=1744)$, which is on the skeptical side of undecided.

There was no difference in mean scores related to country of residence or birth for the countries with the largest subgroups of respondents.

\section{Validity of one-item conspiracy beliefs scale as conspiracy mentality}

The one-item measure (CMQ1) was highly correlated with the twelve conspiracy theory questions scale (CT-10) $(\mathrm{r}=0.58, \mathrm{p}<0.001)$.

As mentioned above, the conspiracy theory questions factored into two, weakly related groups. When we removed questions about conspiracy stereotypes regarding Muslims and Jews (CS-2) from the calculation, the correlation between CMQ1 and the ten remaining conspiracy questions (CT-10) increased $(r=0.63, p<0.001)$. For the two items of minorities alone, the correlation was small $(\mathrm{r}=0.14, \mathrm{p}<0.001)$.

\section{Paranormal beliefs and conspiracy theory}

Paranormal beliefs (PBS-23) correlated strongly with conspiracy beliefs (CT$10, \mathrm{r}=0.59, \mathrm{p}<0.001)$. Scores on paranormal beliefs also correlated with conspiracy mentality $(\mathrm{r}=0.41, \mathrm{p}<0.001)$, but were unrelated to conspiracy stereotypes about Muslims and Jews (CS-2; $\mathrm{r}=0.04, \mathrm{p}>0.05$ ).

Principal component analysis showed four sub-groups of paranormal beliefs. All were positively related to conspiracy beliefs. The strongest correlation with conspiracy beliefs was for UFO-related beliefs (PBS-UFO, $r=0.61$, 
$\mathrm{p}<0.001$ ), and this was also the only subgroup where the relation to CS-2 was significant $(\mathrm{r}=0.16, \mathrm{p}<0.001)$.

\section{SDO-E and conspiracy theory}

SDO-E correlated positively with conspiracy stereotypes (CS-2), $r=0.28, p$ $<0.001$. The correlation with the other conspiracy beliefs was very weak $(r=$ $0.06, \mathrm{p}<0.01)$.

There was no correlation between SDO-E and conspiracy mentality (CMQ1), and the correlation between SDO-E and paranormal beliefs was negative $(\mathrm{r}=-0.28, \mathrm{p}<0.001)$.

\section{Sex differences}

We conducted independent samples t-tests on differences in beliefs between the sexes. There was no difference between men and women on conspiracy beliefs. Their mean score on the ten items was almost identical. While both clearly disagreed with conspiracy stereotype-beliefs about Jews and Muslims, men $(\mathrm{M}=2.00, \mathrm{SD}=1.13)$ scored slightly, but significantly higher than women $(\mathrm{M}=1.87, \mathrm{SD}=1.11), t(1678)=2.26, \mathrm{p}<0.05, \mathrm{~d}=0.11)$.

Women were more inclined to paranormal belief (PBS-23, men $\mathrm{M}=2.58$, $\mathrm{SD}=0.71$; women, $\mathrm{M}=2.39, \mathrm{SD}=0.70, t(1681)=5.63, \mathrm{p}<0.001, \mathrm{~d}=0.3)$.

Men $(\mathrm{M}=1.96, \mathrm{SD}=0.92)$ scored significantly higher than women on SDO-E $(\mathrm{M}=1.65, \mathrm{SD}=0.77 ; t(902.8)=6.90, \mathrm{p}<0.001, \mathrm{~d}=0.37)$.

Those reporting as "other" had a lower means score on SDO-E and both sets of conspiracy beliefs. They scored midway between men and women on paranormal beliefs.

\section{Education}

There was a small, but significant negative correlation $(\mathrm{r}=-0.18 ; \mathrm{p}<0.001)$ between four levels of education and conspiracy beliefs. There were also significant differences between the four groups of level of education and conspiracy beliefs $\mathrm{F}(3,1740)=21.89, \mathrm{p}<0.001)$. Post-hoc, independent samples $\mathrm{t}$-tests were used to compare the different groups. There was no difference between some college and no college. Those with a master's degree or higher scored lower on conspiracy beliefs than both those with a bachelor's degree, those with only some college, and those with no college. The largest difference in mean conspiracy belief scores, between higher degree $(\mathrm{M}=2.77$, $\mathrm{SD}=0.78)$ and only some college $(\mathrm{M}=2.37, \mathrm{SD}=0.85 ; t(1033)=7.84, \mathrm{p}$ $<0.001)$, is moderate $(\mathrm{d}=0.49)$.

(C) Equinox Publishing Ltd. 2018 
There was a negative correlation between educational levels and paranormal beliefs $(\mathrm{r}=-0.21 ; \mathrm{p}<0.001)$. There were also differences between groups of level of education and the level of paranormal beliefs, $\mathrm{F}(3,1743)=28.37$, $\mathrm{p}<0.001$. There was no difference between some college and no college. Post hoc, independent samples t-tests showed that the largest difference was between holding a lower degree $(\mathrm{M}=2.51, \mathrm{SD}=0.69)$ and having only some college $(\mathrm{M}=2.28, \mathrm{SD}=0.69 ; t(1131)=5.47, \mathrm{p}<0.001, \mathrm{~d}=0.33$.

\section{Political self-identification}

The vast majority of respondents self-identified as left-to-center on the political spectrum, with more than $60 \%$ inside the $1-3$ value and a mere $3.1 \%$ on the corresponding right. We grouped them into four groups of very different size: left (1-3 on the scale, $\mathrm{N}=1062)$, center ( $4-7, \mathrm{~N}=424)$, right $(8-10, \mathrm{~N}$ $=55)$, and "apolitical" ( $11, \mathrm{~N}=201)$. The final analysis was run on the left to right, with the "apolitical" left out. ${ }^{2}$

One-way ANOVA suggested there were differences between political groups in conspiracy beliefs (CT-10), $\mathrm{F}(2,1538)=7.07, \mathrm{p}=0.001$. Post hoc, independent samples t-tests showed that there was no significant difference between left and right with regard to conspiracy beliefs (CT-10), and no difference between center and right. There was a small, significant difference between left and center, with the center being slightly more inclined towards belief (left: $\mathrm{M}=2.6, \mathrm{SD}=0.82$, center: $\mathrm{M}=2.43, \mathrm{SD}=0.86, t(1484)=3.67$, $\mathrm{p}<0.001, \mathrm{~d}=0.20)$.

One-way ANOVA showed significant differences between all political groups for conspiracy stereotypes (CS-2), F $(2,1538)=44.03, \mathrm{p}<0.001$. Post hoc, independent t-tests showed that the largest difference was between left and right, with the right still disbelieving, but by far more inclined towards a conspiratorial stance than the left was (left: $\mathrm{M}=1.70, \mathrm{SD}=1.07$, right: $\mathrm{M}=2.73, \mathrm{SD}=1.06, t(115)=1.26, \mathrm{p}<0.001, \mathrm{~d}=0.97)$.

\section{Political activity}

Respondents report extremely high voter activity: $74.6 \%$ reported voting in the latest local election and $85.8 \%$ in the latest national election. There was a significant correlation between not voting in the latest national election and conspiracy beliefs. National voters were slightly lower in conspiracy beliefs $(\mathrm{M}=2.55, \mathrm{SD}=0.83)$ than non-voters $(\mathrm{M}=2.34, \mathrm{SD}=0.93, t(1733)=$ $3.58, \mathrm{p}<0.001, \mathrm{~d}=0.21)$. Participation in local elections had no effect.

2. Those reporting to be apolitical typically scored between center and right on conspiracy beliefs.

(C) Equinox Publishing Ltd. 2018 


\section{Regression analyses}

We conducted hierarchical multiple regression on variables significant for CT-10 and CS-2. Table 2 provides the bivariate correlations for the possible predictors. For the ten conspiracy theories, CMQ1, the different paranormal sub-scales, SDO-E, and educational levels combined yielded an $\mathrm{R}^{2}=0.54$. (Table 3).

Table 2. Pearson Correlations Between Conspiracy Theory Beliefs, Paranormal Belief-factors, Political affiliation, Social Dominance Orientation, and Education . N=1547-1754

$\begin{array}{llllllllll}1 & 2 & 3 & 4 & 5 & 6 & 7 & 8 & 9 & 10\end{array}$

1 Conspiracy beliefs

2 Consp. stereotypes $\quad .06^{* *}$

3 Conspiracy mental. $.63^{* * *} .14^{* * *}-$

4 Education $\quad-.18^{* * *}-.12^{* * *}-.17^{* * *}-$

5 SDO-E $\quad-.11^{* * *} .28^{* * *}-.01 \quad-.04 \quad-$

6 Political affiliation $-.09^{* * *} .23^{* * *} .11^{* * *}-.11^{* * *} .37^{* * *}$ -

7 New Age Strict $\quad .39^{* * *}-.02 \quad .26^{* * *}-.15^{* * *}-.41^{* * *}-.05^{*}$

8 Karma-beliefs $\quad .33^{* * *}-.01 \quad .21^{* * *}-.10^{* * *}-.23^{* * *} \quad .01 \quad .45^{* *} \quad$ -

9 UFO/ETI-beliefs $.61^{* * *} .15^{* * *} .50^{* * *}-.26^{* * *}-.07^{* *}-.13^{* * *} .45^{* * *} .40^{* *}$ -

10 New Age wide $\quad .51^{* * *} \quad .02 \quad .34^{* * *}-.17^{* * *}-.22^{* * *}-.03 \quad .51^{* * *} .58^{* * *} \quad .56^{* * *}$ -

Note. ${ }^{*} \mathrm{p}<.05,{ }^{* *} p<.01,{ }^{* * *} p<.001, \bullet$ Scored left-right, "apolitical" excluded.

Table 3. Predictors of conspiracy beliefs $(\mathrm{n}=1535)$.

$\begin{array}{lccc}\text { Predictor } & B(S . E) & B & T \\ \text { Conspiracy mental. } & .147(.007) & .409 & 20.313^{* * *} \\ \text { New Age Strict } & .061(.023) & .063 & 2.675^{* *} \\ \text { Karma-beliefs } & -.005(.019) & -.005 & -.247 \\ \text { UFO/ETI-beliefs } & .229(.019) & .281 & 11.778^{* * *} \\ \text { New Age wide } & .184(.025) & .178 & 7.255^{* * *} \\ \text { SDO-E } & -.030(.021) & -.030 & -1.435 \\ \text { Education } & -.005(.015) & -.005 & -.301 \\ \text { Political affiliation } & -.025(.029 & -.016 & -.846\end{array}$

Note. Adjusted $\mathrm{R}^{2}=.54,{ }^{*} \mathrm{p}<.05,{ }^{* *} \mathrm{p}<.01,{ }^{* * *} \mathrm{p}<.001$

(C) Equinox Publishing Ltd. 2018 
For CS-2, the combined effect of the model yielded $\mathrm{R}^{2}=0.12$. SDO-E, CMQ1, political affiliation, and UFO-beliefs all contributed unique variance, with SDO-E and political affiliation contributing most strongly. (Table 4)

Table 4. Predictors of conspiracy stereotypes about Jews and Muslims ( $\mathrm{n}=1535)$.

$\begin{array}{lccc}\text { Predictor } & B(S . E) & B & T \\ \text { Conspiracy mental. } & .032(.013) & 068 & .2 .459^{*} \\ \text { New Age Strict } & .047(.041) & .036 & 1.146 \\ \text { Karma-beliefs } & -.009(.035) & -.008 & -.253 \\ \text { UFO/ETI-beliefs } & .121(.035) & .113 & 3.440^{* * *} \\ \text { New Age wide } & -.055(.046) & -.040 & -1.196 \\ \text { SDO-E } & .342(.038) & .254 & 8.892^{* * *} \\ \text { Education } & -.086(.029) & -.074 & -2.959^{* *} \\ \text { Political affiliation } & .228(.053) & .112 & 4.268^{* * *}\end{array}$

Note. Adjusted $\mathrm{R}^{2}=.13,{ }^{*} \mathrm{p}<.05,{ }^{* *} \mathrm{p}<.01,{ }^{* * *} \mathrm{p}<.001$

\section{Discussion}

In this case sample of Neopagans, the one-item conspiracy beliefs scale performed well as a measure of general conspiracy beliefs, with the same directional elements as found for the five-item measure of Imhoff and Bruder (2014). For our population, it seems to work decently as a measure of general conspiracy mentality.

Respondents leaned more towards disavowing the one-item measure of conspiracy mentality than the conspiracy items themselves. This may relate to the fact that Lantian et al.'s question is unambiguously framed in terms of wellknown, stigmatized, but much-believed, conspiracy theories, with its explicit references to 9/11, and the deaths of JFK and Princess Diana. The other conspiracy theories, with the exception of those about Jews and Muslims, do not carry the same baggage, and may seem more epistemically neutral. When we look at the content of the specific items of both paranormal and conspiracy beliefs, we see that those that are most clearly in breach of academicallyaccepted knowledge find the least favor.

The explicit tie to narratives known to be considered false accounts of conspiracy is a strong point in CMQ1's favor. That is its intended role. But when conspiracy beliefs are stigmatized, one might in a case like this suspect that clear markers of such labels could arouse negative, group-protective reactions:

(C) Equinox Publishing Ltd. 2018 
"this is not who we are." Pace Wood (2016), one way of interpreting the data is that the label "conspiracy theory" still carries enough stigma that those consciously representing "the face" of Paganism would hesitate in identifying explicitly with a clear marker. This may be one reason why responses to the single conspiracy mentality item are again on the skeptical side, while the responses to more generic conspiracy allegations directed against powerful agents are on the believing side.

While Pagans stand out ideologically and religiously from the larger population, the factors at work in the conspiracy beliefs of the general population hold up well. The single conspiracy mentality item correlated well with the ten-item conspiracy beliefs scale, where it explained the larger part of the variance. Conspiracy mentality was the primary predictor of conspiracy beliefs; however, paranormal beliefs were not far behind. Even when controlling for conspiracy mentality, scores on paranormal beliefs explained a good part of the variance. This again suggests that there are dimensions to conspiracy beliefs covered by factors underlying paranormal beliefs that are not overlapping with our measure of conspiracy mentality.

Education affected both conspiracy beliefs and paranormal beliefs negatively, although at different stages of education: conspiracy beliefs were most strongly affected (i.e. reduced) at the highest degrees of education. There are two, partially complementary mechanisms that may explain this, learning an analytical thinking style (see Swami et al. 2014), and general cognitive ability (Ståhl and van Prooijen, 2018). Academic socialization, acquiring and accepting academic knowledge production seems to play a role in the current sample; paranormal and conspiracy beliefs correlate negatively with current level of education. Learning an analytical thinking style (Swami et al., 2014) would be one part of this picture. However, the larger part of the negative association between conspiracy beliefs and education occurs at the highest levels of education. ${ }^{3}$ This lends, in our opinion, indirect support to Ståhl and van Prooijen's argument (2018) that general cognitive ability is also central to the effect of education.

While the paranormal beliefs score was one of the major factors accounting for variations in conspiracy beliefs, some were more strongly correlated to conspiracy beliefs than others. This may be due to the specific content of the beliefs. Beliefs about UFOs and alternative history at the very least imply conspiracies of silence, and for a highly educated, reflective audience, one might expect that this implication has been absorbed and made explicit. It is therefore not surprising that they correlate strongly with other conspiracy

3. Indeed, holding a doctorate accounted for most of the variance.

(C) Equinox Publishing Ltd. 2018 
theories. However, we deem it of significance to the debate over how surprising the establishment of a New Age conspiracy culture ("conspirituality") should be considered (Asprem and Dyrendal 2015, in press; Ward and Voas 2011), that the broad set of ideas corresponding to New Age-beliefs are also strongly associated with conspiracy beliefs. This lends credibility to the argument that current, often highly egalitarian forms of alternative religion should be expected to include conspiracy beliefs - at least directed "upwards" against powers-that-be.

This relates to another aspect of conspiracy beliefs that the conspiracy mentality explained less well. Conspiracy theories fell into two clearly different groups with different explanations. As expected (Imhoff and Bruder, 2014), conspiracy mentality predicted responses to conspiracy beliefs about half-hidden powerful actors well. It did not however, predict scores on what we have interpreted as conspiracy stereotypes about two religious minorities very well. Since Pagans in general tend to believe that people are and should be equal, it is no surprise that they are highly skeptical towards conspiracy theories about other religious minorities. Contrary to Lantian et al. $(2016,9)$, we found that for our population there were two different dimensions to conspiracy beliefs, and their measure only did well for one of them. Also, contrary to Imhoff and Bruder (2014, Study 2), and contrary to Imhoff's generalized summary, we found no "intrinsic affinity" (Imhoff 2015, 125) between conspiracy mentality and anti-Semitism as measured by our one item on Jewish conspiracy in this group. We had expected that the egalitarian Pagan ethos espoused by the likely (and, as it turned out, actual) respondents to the survey would influence responses to assertions about conspiracy theories regarding other minorities, so that social dominance orientation would play a larger role. Scores on the anti-egalitarian subscale (SDO-E) of the social domination orientation scale (SDO 6) was the largest contributor to the difference in scores on conspiracy theories about religious minorities, but the effect was relatively small, even when combined with political affiliation, which as expected was the other important factor explaining conspiracy stereotypes.

Education contributed in a small way, and sex differences also played a minor role here. Men generally score higher than women on social dominance, and this was again the case, going some way towards explaining the small difference in scores on conspiracy theories about religious minorities. For other conspiracy beliefs, there was no difference between the sexes.

There is a considerable debate as to whether extreme political affiliation is related to conspiracy beliefs (e.g. van Prooijen, Krouwel, and Pollet, 2015; Uscinski and Parent 2014).

(C) Equinox Publishing Ltd. 2018 
In our material, we found no basis for this association. Those identifying as political centrist scored higher on general conspiracy beliefs than either extreme. With regard to conspiracy stereotypes about religious minorities, there was a general tendency towards more belief the further respondents were on the right. This is very likely related to the fact that the extreme left in this population identified as egalitarian, rather than holding authoritarian leftist attitudes, while the more rightwards leaning were less egalitarianminded.

Contrary to our expectations, the current sample of Neopagans does not support the political extremes hypothesis of conspiracy beliefs. The competing hypothesis about conspiracy beliefs and politics stresses political alienation and outsider status (e.g. Uscinski and Parent 2014; Jolley and Douglas 2014). We found some support for this approach in a weak association between reporting lack of political participation and conspiracy beliefs.

\section{Limitations and future research}

These particular survey data were gathered from a convenience sample consisting of a politically highly left-skewed sample of very highly educated, motivated members of a religious minority. The relationships and mechanisms explored in our investigation build on previous research on both general populations and student data. Where our findings support previous studies, they may be interpreted to emphasize the robustness of these mechanisms; where they do not, they should be interpreted with caution, and the relationships between factors should be reproduced before attempting to generalize from them.

This survey was not primarily designed to study conspiracy beliefs, and some of the measures were forced by circumstance to be more restricted. A full scale of social dominance orientation might yield more explanatory power; especially in combination with a more balanced political variance. For groups similar to Pagans, Altemeyer's Right-Wing Authoritarianism scales will continue to be problematic, but one might profit by testing the fouritem authoritarianism index instead (Stenner 2005). The questionnaire could ideally have drawn from a wider sample and included more well-known conspiracy theories. While we have little reason to think this would impact the relations uncovered above, it may impact levels of beliefs, especially among those with higher education-although this might not impact relationships between factors. With regard to what we have interpreted as "conspiracy stereotypes," follow-up studies should include testing stereotype contents and evaluation of relative power for different groups.

(C) Equinox Publishing Ltd. 2018 
In our sample, as well as generally (e.g. Aarnio and Lindeman 2005; Irwin 2009, 56), women score significantly higher than men on paranormal beliefs. Such beliefs are again clearly correlated with conspiracy beliefs (e.g. Darwin et al. 2011; Bruder et al. 2013). The latter are however, highly likely to be equally distributed among men and women. This makes us curious, and raises a question that should be addressed in future research: if it holds true that women are generally more prone to paranormal beliefs, why does the correlation between paranormal beliefs and conspiracy beliefs not result in an unequal distribution of conspiracy beliefs among men and women? Further research needs to consider mechanisms that regulate the associations between these factors.

\section{Conclusions}

We found strong indications that the one-item conspiracy beliefs scale predicts conspiracy beliefs directed towards hidden, powerful agents. In this sense, we reproduce the findings of Lantian et al. (2016). However, it underperformed on beliefs about religious minorities. While our respondents differ from a general population, the dimensions of conspiracy beliefs are clearly enough delineated that it could be relevant to develop a measure of conspiracy beliefs that covers 'conspiracy stereotypes' better.

The two multivariate analyses suggest that while the one-item conspiracy beliefs scale explains the largest part of the variance in conspiracy beliefs, a large part of the variance is also explained by aspects of paranormal beliefs. The one-item conspiracy beliefs scale predicts conspiracy stereotypes about religious minorities only to a small degree. When controlling for social dominance orientation and political orientation, these explained more of the variance. In addition, there were effects of educational level and some paranormal beliefs. This suggests that conspiracy belief is not a one-dimensional construct, and that the one-item conspiracy beliefs scale is a better predictor of conspiracy beliefs about powerful, hidden agents than about religious outgroups.

\section{References}

Aarnio, K. and M. Lindeman.

2005. "Paranormal beliefs, education, and thinking styles." Personality and Individual Differences 39: 1227-1236.

Aho, J. A.

1990. The Politics of Righteousness. Idaho Christian Patriotism. Seattle: University of Washington Press.

(C) Equinox Publishing Ltd. 2018 
Altemeyer, R. A.

1981. Right-Wing Authoritarianism. Winnipeg: University of Manitoba Press.

Asprem, E. and A. Dyrendal.

2015. "Conspirituality reconsidered: How surprising and how new is the confluence of spirituality and conspiracy theory?" Journal of Contemporary Religion 30(3): 367-382

In press "Close companions? Esotericism and conspiracy theories." In Handbook of Conspiracy Theory and Contemporary Religion, edited by A. Dyrendal, D. G. Robertson and E. Asprem, xx-xx. Leiden: Brill.

Aupers, S.

2012. “Trust Noone': Modernization, paranoia, and conspiracy culture." European Journal of Communication 27(1): 22-34.

Bader, C. D., F. C. Mencken and J. O. Baker.

2010. Paranormal America. New York: New York University Press.

Barkun, M.

1994. Religion and the Racist Right. Chapel Hill: The University of North Carolina Press.

2003. A Culture of Conspiracy. Berkeley: University of California Press.

Barron, D., K. Morgan, T. Towell, B. Altemeyer and V. Swami.

2014. "Associations between schizotypy and conspiracist ideation." Personality and Individual Differences 70: 156-159.

Barron, D., A. Furnham, L. Weis, K. D. Morgan, T. Towell and V. Swami.

2018. "The relationship between schizotypal facets and conspiracist beliefs via cognitive processes." Psychiatry Research 259: 15-20.

Baylor University.

2005. The Baylor Religion Survey, Wave 1. Waco, TX: Baylor Institute for Studies of Religion.

Berger, H. A.

2009. "Contemporary paganism by the numbers." In Handbook of Contemporary Paganism, edited by J. R. Lewis and M. Pizza, 153-170. Leiden: Brill.

Berger, H. A., E. A. Leach and L. S. Shaffer.

2003. Voices from the Pagan Census: A National Survey of Witches and Neo-Pagans in the United States. Columbia: University of South Carolina Press.

Bilewicz, M., A. Cichocka and W. Soral, eds.

2015. The Psychology of Conspiracy. London: Routledge.

Brotherton, R. and C.C. French.

2015. "Intention seekers: Attention seekers and biased attribution of intentionality." PLoS ONE 10(5): e0124125.

(C) Equinox Publishing Ltd. 2018 
Brotherton, R., C. C. French and A. Pickering.

2013. "Measuring conspiracy theories: The generic conspiracist beliefs scale." Frontiers in Psychology 4: 279

Bruder, M., P. Haffke, N. Neave, N. Nouripanah and R. Imhoff.

2013. "Measuring individual differences in generic beliefs in conspiracy theories across cultures: Conspiracy mentality questionnaire." Frontiers in Psychology 4: 225

Butter, $M$.

2014. Plots, Designs, and Schemes. American Conspiracy Theories from the Puritans to the Present. Berlin: Walter de Gruyter.

Butter, M. and M. Reinkowski, eds.

2014. Conspiracy Theories in the United States and the Middle East. A Comparative Approach. Berlin: Walter de Gruyter.

Dagnall, N., K. Drinkwater, A. Parker, A. Denovan and M. Parton.

2015. "Conspiracy theory and cognitive style: A worldview." Frontiers in Psychology 6: 206. http://dx.doi.org/10.3389/fpsyg.2015.00206

Darwin, H., N. Neave and J. Holmes.

2011. "Belief in conspiracy theories: The role of paranormal belief, paranoid ideation and schizotypy." Personality and Individual Difference 50(8): 12891293.

Douglas, K. M., R. M. Sutton, M. J. Callan, R. J. Dawtry and A. J. Harvey.

2016. "Someone is pulling the strings: Hypersensitive agency detection and belief in conspiracy theories." Thinking and Reasoning 22: 57-77.

Dyrendal, A.

2017. "New Age and Norwegian 'conspirituality'." In New Age in Norway, edited by I. S. Gilhus, S-E Kraft and J. R. Lewis,159-181. Sheffield: Equinox.

Dyrendal, A., D. G. Robertson and E. Asprem, eds.

In press Handbook of Conspiracy Theory and Contemporary Religion. Leiden: Brill.

Farias, M., G. Claridge and M. Lalljee.

2005. "Personality and cognitive predictors of new age practices and beliefs." Personality and Individual Differences 39: 979-989.

Farias, M. and P. Granqvist.

2006. "The psychology of the New Age." In Handbook of New Age, edited by D. Kemp and J. R. Lewis, 123-150. Leiden: Brill.

Gardell, M.

2003. Gods of the Blood: The Pagan Revival and White Separatism. Durham: Duke University Press.

(C) Equinox Publishing Ltd. 2018 
Goertzel, T.

1994. "Belief in conspiracy theories." Political Psychology 154: 731-742

Goodrick-Clarke, N.

2003. Black Sun: Aryan Cults, Esoteric Nazism and the Politics of Identity. New York: New York University Press.

Gray, M.

2010. Conspiracy Theories in the Arab World. New York: Routledge

Ho, A. K., J. Sidanius, F. Pratto, S. Levin, L. Thomsen, N. Kteily and J. SheehySkeffington.

2012. "Social dominance orientation: Revisiting the structure and function of a variable predicting social and political attitudes." Personality and Social Psychology Bulletin 385: 583-606.

Ho, A. K., J. Sidanius, N. Kteily, J. Sheehy-Skeffington, F. Pratto, K. E. Henkel, R.

Foels and A. L. Stewart.

2015. "The nature of social dominance orientation: Theorizing and measuring preferences for intergroup inequality using the new SDO7 scale." Journal of Personality and Social Psychology 1096: 1003-1028.

Hofstadter, R.

1964. The Paranoid Style in American Politics and Other Essays. New York: Alfred A. Knopf

Imhoff, R.

2015. "Beyond right-wing authoritarianism. conspiracy mentality as an incremental predictor of prejudice." In The Psychology of Conspiracy, edited by M. Bilewicz, A. Cichocka and W. Soral, 122-141. London: Routledge.

Imhoff, R. and M. Bruder.

2014. "Speaking un-truth to power: Conspiracy mentality as a generalised political attitude." European Journal of Personality 28: 25-43

Irwin, H. J.

2009. The Psychology of Paranormal Beliefs: A Researchers Handbook. Hertfordshire: University of Hertfordshire Press.

Jolley, D. and K. M. Douglas.

2014. "The social consequences of conspiracism: Exposure to conspiracy theories decreases intentions to engage in politics and to reduce one's carbon footprints." British Journal of Psychology, 105, 35-56.

Krouwel, A., Y. Kutiyski, J-W. van Prooijen, J. Martinsson, E. Markstedt.

2017. "Does extreme political ideology predict conspiracy beliefs, economic evaluations and political trust? evidence from Sweden.” Journal of Social and Political Psychology 5(2): 435-462.

(C) Equinox Publishing Ltd. 2018 
Lantian, A., D. Muller, C. Nurra and K. M. Douglas.

2016. "Measuring belief in conspiracy theories: Validation of a French and English single-item scale." International Review of Social Psychology 291: 1-14

Lewis, J. R. and I. B. Tøllefsen.

2013. "Gender and paganism in census and survey data." The Pomegranate 151(2): 61-78.

Lewis, J. R., S. E. Currie and M. P. Oman-Reagan.

2016. "The religion of the educated classes revisited: New religions, the non-religious, and educational levels." Journal for the Scientific Study of Religion 551: 91-104.

Lindeman, M. and K. Aarnio.

2006. "Paranormal beliefs: Their dimensionality and correlates." European Journal of Personality 20: 585-602.

Lobato, E., J. Mendoza, V. Sims and M. Chin.

2014. "Examining the relationship between conspiracy theories, paranormal beliefs and pseudoscience acceptance in a university population." Applied Cognitive Psychology 28: 617-625

Oliver, J. E. and T. J. Wood.

2014. "Conspiracy theories and the paranoid styles of mass opinion." American Journal of Political Science 584: 952-966.

Orenstein, A.

2002. "Religion and paranormal belief." Journal for the Scientific Study of Religion 41: 301-311

Pratto, F., L. M. Stallworth and J. Sidanius.

1997. "The gender gap: Differences in political attitudes and social dominance orientation." British Journal of Social Psychology 36(1): 49-68.

Robertson, D. G.

2016. UFO's, Conspiracy Theories, and the New Age: Millennial Conspiracism. London: Bloomsbury Academic.

Roeland, J., S. Aupers and D. Houtman.

2012. "Fantasy, conspiracy, and the romantic legacy: max weber and the spirit of contemporary popular culture." In Handbook of Hyper-Real Religion, edited by A. Possamai, 401-422. Leiden: Brill.

Sidanius, J. and F. Pratto.

1999. Social Dominance: An Intergroup Theory of Social Hierarchy and Oppression. Cambridge: Cambridge University Press.

(C) Equinox Publishing Ltd. 2018 
Stenner, K.

2005. The Authoritarian Dynamic. Cambridge: Cambridge University Press.

Stone, A., M. R. McDermott, A. Abdi, B. Cornwell, Z. Matyas, R. Reed and R.

Watt.

2018. "Development and validation of the multi-dimensional questionnaire of scientifically unsubstantiated beliefs." Personality and Individual Differences 128: $146-156$

Ståhl, T. and J-W. van Prooijen.

2018. "Epistemic rationality: Skepticism against unfounded beliefs requires sufficient cognitive ability and motivation to be rational." Personality and Individual Differences 122: 155-163

Swami, V., R. Coles, S. Stieger, J. Pietschnig, A. Furnham, S. Rehim and M.

Voracek.

2011. "Conspiracist ideation in Britain and Austria: Evidence of a monological belief system and associations between individual psychological differences and real-world and fictitious conspiracy theories." British Journal of Psychology 102: 443-463

Swami, V., M. Voracek, S. Stieger, U. S. Tran and A. Furnham.

2014. „Analytic thinking reduces belief in conspiracy theories.” Cognition 133: 572-585.

Tobacyk, J. J.

2004. "A revised paranormal beliefs scale." International Journal of Transpersonal Studies 231: 94-98.

Tobacyk, J. J. and G. Milford.

1983. "Belief in paranormal phenomena: Assessment instrument development and implications for personality functioning." Journal of Personality and Social Psychology. 445: 1029-1037.

Uscinski, J. E. and J. M. Parent.

2014. American Conspiracy Theories. Oxford: Oxford University Press

Van der Tempel, J. and J. E. Alcock.

2015. "Relationships between conspiracy mentality, hyperactive agency detection, and schizotypy: Supernatural forces at work?" Personality and Individual Differences 82: 136-141.

Van Prooijen, J-W.

2017. "Why education predicts decreased belief in conspiracy theories." Applied Cognitive Psychology 31(1): 50-58.

(C) Equinox Publishing Ltd. 2018 
Van Prooijen, J-W., A. P. M. Krouwel and T. V. Pollet.

2015. "Political extremism predicts belief in conspiracy theories." Social Psychological and Personality Science 6: 570-578.

Winiewski, M., W. Soral and M. Bilewicz.

2015. "Conspiracy theories on the map of stereotype content." In The Psychology of Conspiracy, edited by M. Bilewicz, A. Cichocka and W. Soral, 23-41. London: Routledge.

Wood, M. J.

2016. "Some dare call it conspiracy: Labeling something a conspiracy theory does not reduce belief in it." Political Psychology 375: 695-705

Wood, M. J. and K. M. Douglas.

In press "Are conspiracy theories a surrogate for God?" In Handbook of Conspiracy Theory and Contemporary Religion, edited by A. Dyrendal, D. G. Robertson, xx-xx and E. Asprem, xx-xx. Leiden: Brill. 
